\title{
Response: Commentary: Blood Flow Restriction Exercise: Considerations of Methodology, Application, and Safety
}

\author{
Tim Kambic ${ }^{1 *}$, Borut Jug ${ }^{2,3 t}$ and Mitja Lainscak ${ }^{2,4,5 t}$ \\ ${ }^{1}$ Cardiac Rehabilitation Unit, Department of Research and Education, General Hospital Murska Sobota, Murska Sobota, \\ Slovenia, ${ }^{2}$ Faculty of Medicine, University of Ljubljana, Ljubljana, Slovenia, ${ }^{3}$ Division of Internal Medicine, Department of \\ Vascular Diseases, University Medical Centre Ljubljana, Ljubljana, Slovenia, ${ }^{4}$ Division of Cardiology, General Hospital Murska \\ Sobota, Murska Sobota, Slovenia, ${ }^{5}$ Faculty of Natural Sciences and Mathematics, University of Maribor, Maribor, Slovenia
}

Keywords: blood flow restriction, resistance training, exercise pressor reflex, coronary artery disease, cardiac rehabilitation

\section{A Commentary on}

OPEN ACCESS

Edited by: Can Ozan Tan, Harvard Medical School, United States

Reviewed by: Stefanos Volianitis, Qatar University, Qatar

*Correspondence:

Tim Kambic tim.kambic@gmail.com

tThese authors have contributed equally to this work and share senior authorship

Specialty section: This article was submitted to

Exercise Physiology, a section of the journal

Frontiers in Physiology

Received: 08 February 2021 Accepted: 26 February 2021

Published: 29 March 2021

Citation:

Kambic T, Jug B and Lainscak M (2021) Response: Commentary: Blood Flow Restriction Exercise: Considerations of Methodology,

Application, and Safety.

Front. Physiol. 12:665568.

doi: 10.3389/fphys.2021.665568
Commentary: Blood Flow Restriction Exercise: Considerations of Methodology, Application, and Safety

by Spranger, M. D. (2020). Front. Physiol. 11:599592. doi: 10.3389/fphys.2020.599592

We read with great interest the recent comprehensive guidelines for the implementation of blood flow-restricted resistance exercise (BFR-RE) into sports and clinical practice. The authors provided an extensive description of the mechanism and training application and addressed many important safety considerations (Patterson et al., 2019). With the potential of BFR exercise expanded to clinical settings [such as in orthopedic (Hughes et al., 2017) and cardiovascular patients (Madarame et al., 2013; Tanaka and Takarada, 2018; Kambič et al., 2019)], many previous reviews have raised safety concerns (Spranger et al., 2015; Oliveira et al., 2019). These are due to potential peripheral ischemiainduced hyperactivity of III and IV nerve afferents that could evoke muscle metabo- and/or mechanoreflex (e.g., the exercise pressor reflex), primarily in cardiovascular patients (Piepoli et al., 2008; Angius and Crisafulli, 2020). Since the guidelines focused mainly on the effects of BFR-RE on cardiovascular response and blood coagulation (Patterson et al., 2019), the recent commentary in the journal also highlighted this important safety issue (Spranger, 2020).

In the commentary, the potential role of exercise pressor reflex during BFR-RE was linked with a higher increase in blood pressure during low-load BFR-RE compared with low-load RE without BFR (Spranger, 2020), as demonstrated in previous studies enrolling healthy adults (Downs et al., 2014; Hori et al., 2020) and older women (Scott et al., 2018). In contrast, one study, not included in the recent commentary (Spranger, 2020), has demonstrated lower blood pressure during low-load BFR-RE [ $30 \%$ of one-repetition maximum (1-RM), 4 sets of 15 repetitions per set, with $60 \mathrm{~s}$ of rest between sets] compared with low-load and high-load RE to failure (Libardi et al., 2017). This indicates that time under BFR is likely a major contributor to more pronounced exercise pressor reflex observed when sets of more than 15 repetitions (Scott et al., 2018; Hori et al., 2020) or sets to volitional fatigue are performed (Downs et al., 2014). Therefore, we agree with the author that future BFR-RE training implementations in cardiovascular rehabilitation settings should take into consideration the duration of time under BFR (e.g., duration of the exercise), applied cuff pressure to the limb, and width of the cuff (Loenneke et al., 2013), as the main mediators of the magnitude of exercise pressor response (Oliveira et al., 2019). 
The implementation of BFR-RE in cardiovascular patients (e.g., coronary artery disease, heart failure, and peripheral artery disease) was addressed only in two hemodynamic studies (Pinto and Polito, 2016; Kambič et al., 2020). Both were included in the commentary (Spranger, 2020), yet we argue that several key findings of our study about BFR-RE safety (e.g., hemodynamic response during exercise) were not discussed thoroughly. Importantly, our study also measured hemodynamic response during low-load BFR-RE at 30 and $40 \%$ of 1-RM (Kambič et al., 2020), in addition to the already mentioned hemodynamic adaptations after BFR resistance training (RT) (Kambič et al., 2019). Prior to BFR-RT intervention, we measured heart rate and blood pressure response to three sets of 8,10 , and 12 repetitions at the intensity of $30 \%$ of $1-\mathrm{RM}$, a lifting cadence of $1 \mathrm{~s}$ of concentric contraction and $2 \mathrm{~s}$ of eccentric contraction, and with $45 \mathrm{~s}$ of rest between sets (Kambič et al., 2020). Heart rate (HR), systolic blood pressure (SBP), and diastolic blood pressure (DBP) increased significantly in the first set (HR: +10 bpm, SBP: $+12 \mathrm{mmHg}$, DBP: $+3 \mathrm{mmHg}$ ), second set (HR: $+14 \mathrm{bpm}$, SBP: $+22 \mathrm{mmHg}$, DBP: $+10 \mathrm{mmHg}$ ), and third set (HR: +18 bpm, SBP: $+13 \mathrm{mmHg}$, DBP: $+3 \mathrm{mmHg}$ ) compared with baseline levels. Furthermore, HR, SBP, and DBP increased significantly from the second set to the third set, while BP was significantly lower after the cuff pressure was released after the third set compared with the second set. All hemodynamic parameters returned to baseline values after the end of BFRRE. After the completion of 8 weeks of BFR-RT intervention, we re-evaluated the hemodynamic response to BFR-RE at the intensity of $40 \%$ of 1-RM. With the exception of lower diastolic pressure in the third set compared with the first of the BFR-RE, leading to a significant set $\times$ intensity interaction $(p=0.027)$, we observed a similar increase in HR and SBP as during the baseline measurement at $30 \%$ of $1-\mathrm{RM}$, with no significant set $x$ intensity interaction. In addition, BFR-RE did not induce any changes in circulating levels of hemostatic markers (D-dimer and fibrinogen) and $\mathrm{N}$-terminal prohormone B-type natriuretic hormone following acute BFR-RE and BFR-RT (Kambič et al., 2020), which is in line with the only study available in coronary artery disease patients (Madarame et al., 2013).

\section{REFERENCES}

Angius, L., and Crisafulli, A. (2020). Exercise intolerance and fatigue in chronic heart failure: is there a role for group III/IV afferent feedback? Eur. J. Prev. Cardiol. 27, 1862-1872. doi: 10.1177/2047487320906919

Downs, M. E., Hackney, K. J., Martin, D., Caine, T. L., Cunningham, D., O'Connor, D. P., et al. (2014). Acute vascular and cardiovascular responses to blood flow-restricted exercise. Med. Sci. Sports Exerc. 46, 1489-1497. doi: 10.1249/MSS.0000000000000253

Franz, A., Berndt, F., Raabe, J., Harmsen, J.-F., Zilkens, C., and Behringer, M. (2020). Invasive assessment of hemodynamic, metabolic and ionic consequences during blood flow restriction training. Front. Physiol.11:617668. doi: $10.3389 /$ fphys.2020.617668

Hori, A., Hasegawa, D., Suijo, K., Nishigaki, K., Ishida, K., and Hotta, N. (2020). Exaggerated pressor response to blood flow restriction resistance exercise is associated with a muscle metaboreflex-induced increase in blood pressure in young, healthy humans. Appl. Physiol. Nutr. Metabol. 46, 182-185. doi: 10.1139/apnm-2020-0491
Despite our novel findings on the safety and efficacy of BFR-RT on muscle strength and vascular function, there remain many methodological limitations and unanswered questions. These should be addressed in future trials before BFR-RE can be routinely included in cardiac rehabilitation. Ideally, future trials should use indirect beat-by-beat methods (photoplethysmography or impendance cardiography) (Downs et al., 2014; Scott et al., 2018) or direct measurements of hemodynamic response using an arterial and venous catheter on the exercising limb (Franz et al., 2020); as these methods are not used routinely, a correlation study with usual hemodynamic monitors (automated BP monitor) should be considered. Future trials should also be designed to study the hemodynamic effects of high-load RE ( $>70 \%$ 1-RM) and low-load RE with and without BFR ( $<40 \% 1-R M)$. In addition, special consideration should be given to the selection of narrow cuffs (Loenneke et al., 2013) and the reduction of time under BFR, with manipulation of the number of sets ( $<3-4$ sets) and repetitions ( $<15$ repetitions per set) (Madarame et al., 2013; Kambič et al., 2019), and lifting cadence ( $1 \mathrm{~s}: 1 \mathrm{~s}$ of concentric and eccentric contraction) (Lamotte et al., 2010) to minimize the (potential) activation of exercise pressor reflex in cardiovascular disease patients.

\section{AUTHOR CONTRIBUTIONS}

TK: writing of the manuscript draft and responsible for the final content. BJ and ML: writing of the manuscript draft. All authors read, critically reviewed, and approved the final version of the manuscript.

\section{FUNDING}

This work was funded by the Slovenian Research Agency (research grant no. J3-9292, Burden of cachexia and sarcopenia in patients with chronic diseases: epidemiology, pathophysiology, and outcomes, and research grant no. J3-9284, Epidemiology, pathophysiology, and clinical relevance of anemia in chronic cardiopulmonary patients). TK received a research fellowship from the Slovenian Research Agency (grant no. 630-72/2019-1).

Hughes, L., Paton, B., Rosenblatt, B., Gissane, C., and Patterson, S. D. (2017). Blood flow restriction training in clinical musculoskeletal rehabilitation: a systematic review and meta-analysis. Br. J. Sports Med. 51, 1003-1011. doi: 10.1136/bjsports-2016-097071

Kambič, T., Novaković, M., Tomažin, K., Strojnik, V., Božič-Mijovski, M., Jug B. (2020). Hemodynamic and hemostatic response to blood flow restriction resistance exercise in coronary artery disease. $J$. Cardiovasc. Nurs. doi: 10.1097/JCN.0000000000000699. [Epub ahead of print].

Kambič, T., Novaković, M., Tomažin, K., Strojnik, V., and Jug, B. (2019). Blood flow restriction resistance exercise improves muscle strength and hemodynamics, but not vascular function in coronary artery disease patients: a pilot randomized controlled trial. Front. Physiol. 10:656. doi: 10.3389/fphys.2019.00656

Lamotte, M., Fleury, F., Pirard, M., Jamon, A., and Borne, P., van de. (2010). Acute cardiovascular response to resistance training during cardiac rehabilitation: effect of repetition speed and rest periods. Eur. J. Cardiovasc. Prev. Rehabil. 17, 329-336. doi: 10.1097/HJR.0b013e328332efdd 
Libardi, C. A., Catai, A. M., Miquelini, M., Borghi-Silva, A., Minatel, V., Alvarez, I., et al. (2017). Hemodynamic responses to blood flow restriction and resistance exercise to muscular failure. Int. J. Sports Med. 38, 134-140. doi: 10.1055/s-0042-115032

Loenneke, J., Fahs, C., Rossow, L., Thiebaud, R., Mattocks, K., Abe, T., et al. (2013). Blood flow restriction pressure recommendations: a tale of two cuffs. Front. Physiol. 4:249. doi: 10.3389/fphys.2013.00249

Madarame, H., Kurano, M., Fukumura, K., Fukuda, T., and Nakajima, T. (2013). Haemostatic and inflammatory responses to blood flow-restricted exercise in patients with ischaemic heart disease: A pilot study. Clin. Physiol. Funct. Imaging 33, 11-17. doi: 10.1111/j.1475-097X.2012.01158.x

Oliveira, M., Meireles, K., Spranger, M. D., O'Leary, D. S., Roschel, H., and Peçanha, T. (2019). Clinical safety of blood flow-restricted training? A comprehensive review of altered muscle metaboreflex in cardiovascular disease during ischemic exercise. Am. J. Physiol. Heart Circ. Physiol. 318, H90-H109. doi: 10.1152/ajpheart.00468.2019

Patterson, S. D., Hughes, L., Warmington, S., Burr, J., Scott, B. R., Owens, J., et al. (2019). Blood flow restriction exercise: considerations of methodology, application, and safety. Front. Physiol. 10:533. doi: 10.3389/fphys. 2019.00533

Piepoli, M. F., Dimopoulos, K., Concu, A., and Crisafulli, A. (2008). Cardiovascular and ventilatory control during exercise in chronic heart failure: role of muscle reflexes. Int. J. Cardiol. 130, 3-10. doi: 10.1016/j.ijcard.2008.02.030

Pinto, R. R., and Polito, M. D. (2016). Haemodynamic responses during resistance exercise with blood flow restriction in hypertensive subjects. Clin. Physiol. Funct. Imaging 36, 407-413. doi: 10.1111/cpf.12245
Scott, B. R., Peiffer, J. J., Thomas, H. J., Marston, K. J., and Hill, K. D. (2018). Hemodynamic responses to low-load blood flow restriction and unrestricted high-load resistance exercise in older women. Front. Physiol. 9:1324. doi: 10.3389/fphys.2018.01324

Spranger, M. D. (2020). Commentary: blood flow restriction exercise: considerations of methodology, application, and safety. Front. Physiol. 11:599592. doi: 10.3389/fphys.2020.599592

Spranger, M. D., Krishnan, A. C., Levy, P. D., O'Leary, D. S., and Smith, S. A. (2015). Blood flow restriction training and the exercise pressor reflex: a call for concern. Am. J. Physiol. Heart Circ. Physiol. 309, H1440-H1452. doi: 10.1152/ajpheart.00208.2015

Tanaka, Y., and Takarada, Y. (2018). The impact of aerobic exercise training with vascular occlusion in patients with chronic heart failure. ESC Heart Fail. 5, 586-591. doi: 10.1002/ehf2.12285

Conflict of Interest: The authors declare that the research was conducted in the absence of any commercial or financial relationships that could be construed as a potential conflict of interest.

Copyright (C) 2021 Kambic, Jug and Lainscak. This is an open-access article distributed under the terms of the Creative Commons Attribution License (CC BY). The use, distribution or reproduction in other forums is permitted, provided the original author(s) and the copyright owner(s) are credited and that the original publication in this journal is cited, in accordance with accepted academic practice. No use, distribution or reproduction is permitted which does not comply with these terms. 